\title{
Exterior Artificial Pancreas Project
}

\author{
Christos Beretas* \\ France
}

\author{
Abstract \\ Objective: Pump size exterior artificial pancreas that will keep the glucose between $120-150 \mathrm{mg} / \mathrm{dl}$.
}

ISSN: 2576-8816

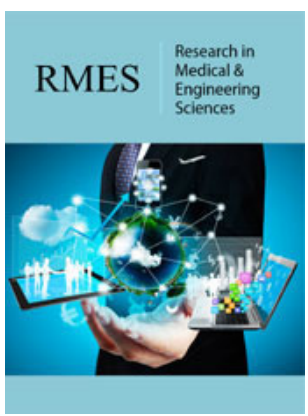

*Corresponding author: Christos Beretas, Paris, France

Submission: 酶 November 22, 2019

Published: 醖January 16, 2020

Volume 8 - Issue 4

How to cite this article: Christos $B$. Exterior Artificial Pancreas Project. Res Med Eng Sci. 8(4).RMES.000692.2020. DOI: 10.31031/RMES.2020.08.000692

Copyright@ Christos Beretas, This article is distributed under the terms of the Creative Commons Attribution 4.0 International License, which permits unrestricted use and redistribution provided that the original author and source are credited.
Method: The whole project based in idea that we should already know one insulin unit how much is able to go down the glucose and one glucagon's unit how much is able to increase the glucose. Less than $120 \mathrm{mg} /$ $\mathrm{dl}$ it uses glucagon's. More than $150 \mathrm{mg} / \mathrm{dl}$ it uses insulin. The pump checks the glucose automatically every 8 minutes. The pump (which is software decision) will choose between insulin or glucagon's base in internal database table with prerequisite glucose values and the insulin or glucagon's units requiring for each glucose value (adaptive database table for each diabetic). The pump (the software) is able to choose how many insulin or glucagon's units it should use (that is not based on what the diabetic will eat, but base on the current glucose level that received from the sensor which is located in human body, needle and sensor are one piece). The insulin should have work duration 8 minutes and works instantly.

Result: I chose $120 \mathrm{mg} / \mathrm{dl}$ as the lowest allowance glucose level because this glucose level is secure for the diabetic (there is a time to prevent big hypoglycemia).

Conclusion: This project offers to diabetic's insulin injections freedom, hypoglycemia prevention, run emergency tests, ideally for all ages, endocrinologists will have the software to adapt the internal database table of the pump for each diabetic needs.

\section{Artificial Pancreas Presentation and Analysis}

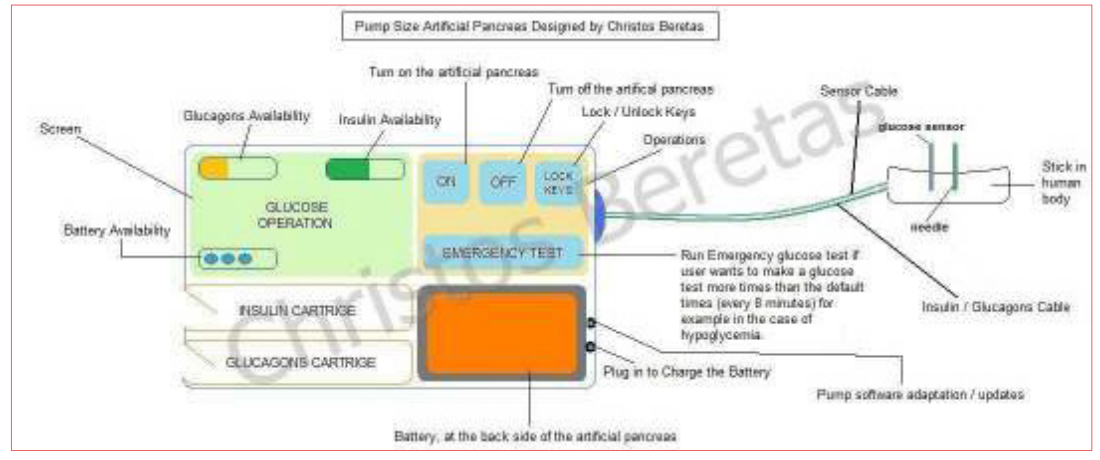

Figure 1:

The pump size exterior artificial pancreas (Figure 1), uses one sensor (the sensor is one material which include the needle that require to inject to human body both glucagon's or insulin, when the sensor is replacing, replace the needle too, is one device with two operations) to collect the current glucose levels from the human body, when the sensor collect the current glucose level, send the data to the artificial pancreas through a cable, then the artificial pancreas read the received glucose value and through table with prerequisites insulin and glucagon's units for each received glucose value decide how many insulin units require to decrease the glucose or how many glucagon's units require to increase the glucose to prevent hypoglycemia. My logic is below $120 \mathrm{mg} / \mathrm{dl}$ to use glucagon's and above $150 \mathrm{mg} / \mathrm{dl}$ use insulin (I chose 120 as the lower level for safety purposes, because the artificial pancreas has the time to increase the glucose in next 8 minutes that will check automatically the glucose and if the glucose goes down will automatically increase it without the diabetic to feel hypoglycemia, I think glucose need some time goes down from $120 \mathrm{mg} / \mathrm{dl}$ until feeling hypoglycemia, I think there is a time to prevent it). The artificial pancreas is remaining standby when the glucose 
is between $120-150 \mathrm{mg} / \mathrm{dl}$. I set the artificial pancreas to make auto glucose tests every 8 minutes, while I added "emergency test" button which the artificial pancreas is able to do current glucose test and chose either glucagon's or insulin, this button is useful for hypoglycemia or hyperglycemias cases.

\section{Usage}

A. The goal of the above pump size exterior artificial pancreas is to keep the glucose between $120-150 \mathrm{mg} / \mathrm{dl}$.

B. Less than $120 \mathrm{mg} / \mathrm{dl}$ it uses glucagon's.

C. More than $150 \mathrm{mg} / \mathrm{dl}$ it uses insulin.

D. The pump checks the glucose automatically every 8 minutes.

E. The pump (which is software decision) will choose between insulin or glucagon's base in internal table.

F. The user by pressing the "emergency test" button is able to do glucose test (extra test) which the pump will decide to use insulin or glucagon's (base on the result).

G. The pump (the software) is able to choose how many insulin or glucagon's units it should use (that is not based on what the diabetic will eat, but base on the current glucose level).

H. Automatically the pump notifies the user for low levels of buttery, insulin, and glucagon's.

I. I chose $120 \mathrm{mg} / \mathrm{dl}$ as the lowest allowance glucose level because this glucose level is secure for the diabetic (there is a time to prevent hypoglycemia) generally the diabetic needs more than
8 minutes to feel hypoglycemia, the pump run automatically tests every 8 minutes. Thus, the pump will prevent the hypoglycemia because have the time to do that.

J. Between the glucose results $(120-150 \mathrm{mg} / \mathrm{dl})$ the artificial pancreas is in standby mode, because these glucose levels are normal for the pump. Also, the from the sensor, while notify the diabetic by continuous sound.

K. Endocrinologists they will have the software to adapt the internal database

L. table of the pump for each diabetic needs.

\section{Synopsis}

There are two important points, the first one is the insulin, the pump automatically run tests every 8 minutes, thus we can't use insulin that have a duration one, three, or six hours, this pump needs insulin that have duration 8 minutes and it should work immediate (we should know both how much one insulin unit decrease the glucose in $\mathrm{mg} / \mathrm{dl}$ and how much one glucagon's unit increase the glucose in $\mathrm{mg} / \mathrm{dl}$ to make the

best table). The second point is the kids with diabetes below of 10 years old require usually less insulin units, this artificial pancreas is not able to determine the age of the people, for example, cannot be use in 10 years old diabetic, because his/her body require less insulin units than a 25 years old or older diabetic. To overcome this limitation, endocrinologists they will have the software to adapt the internal database table of the pump for each diabetic needs including the need that is require for example a 10 -year-old kid. 